\title{
Temporal variation in allele frequencies in the pollen pool of Eucalyptus rhodantha
}

\author{
J. F. Sampson* $\neq$, \\ S. D. Hoppert and \\ S. H. James*
}

\author{
* Department of Botany, The University of Western \\ Australia, Nedlands, Western Australia 6009. \\ $\dagger$ Department of Conservation and Land \\ Management, Western Australian Wildlife Research \\ Centre, P.O. Box 51, Wanneroo, Western Australia \\ 6065 .
}

Investigation of the mallee Eucalyptus rhodantha which has an irregular, protracted flowering period demonstrated that individual plants differ in fecundity and phenology and that allele frequencies in the pollen pool change during the flowering season. Allele frequencies of the pollen pool were estimated by several methods which either assumed temporal homogeneity or took flowering phenology into account. These allele frequencies were compared for their abilities to estimate $t$. The estimates of $t$ based on allele frequencies which took phenology into account were not consistently higher or better than those that did not at any of the four loci surveyed. Changes in the allele frequencies of the pollen pool during the flowering season may contribute to variation between some single-locus estimates of $\hat{t}$ in $E$. rhodantha which assume temporal homogeneity, but it was concluded that they are not the major cause of bias.

\section{INTRODUCTION}

Many quantitative studies of plant mating systems and all investigations of mating systems in Eucalyptus have been based on the mixed mating model in which all matings are classified as either random outcrosses or self-pollinations (Fyfe and Bailey, 1951). A principal assumption of this model is that the outcross pollen pool is genetically homogeneous over maternal parents (Brown and Allard, 1970) so that violation of this assumption occurs if there is temporal or spatial heterogeneity in the distribution of genotypes in the population (Ennos and Clegg, 1982; Schoen and Clegg, 1984). Such violations may lead to significant differences in estimates of the outcrossing rate $(\hat{t})$ for different loci and underestimates of $\hat{t}$ using single locus estimation procedures (Ennos and Clegg, 1982; Bijlsma et al., 1986).

If alleles of marker loci affect or are associated with alleles that affect flowering time then temporal heterogeneity in allele frequencies for these loci in both the ovule and pollen pools may result (Bijlsma et al., 1986) and lead to variation in estimates of mating system parameters (Stam, 1983; Yeh et al., 1983; Bijlsma et al., 1986; O'Malley and Bawa,

¥ Present address: Department of Forest Science, University of Alberta, Edmonton, Canada, T6G 2H1.
1987). Temporal flowering differences have been observed in several plant species (e.g., Frankie et al., 1974; Stern and Roche, 1974; Bawa, 1983; Handel and Le Vie Mishkin, 1984; Wheelwright, 1985) including eucalypts (Florence, 1964; Ashton, 1975).

Fripp et al. (1987) developed a method for taking inter-plant variation in flowering phenology and fecundity into account when estimating allele frequencies in the outcross pollen pool of the massflowering, preferentially outcrossing and predominantly insect-pollinated forest tree Eucalyptus regnans $\mathrm{F}$. Muell. These workers found that when fecundity and flowering phenology were taken into account, allele frequencies at three loci in the outcross pollen pool varied over time but that the temporal heterogeneity did not have a major effect on single-locus maximum likelihood estimates of the level of outcrossing. They suggested that biases introduced by assuming homogeneity of pollen pool allele frequencies may be more severe in plants with more irregular or protracted flowering periods than E. regnans.

Eucalyptus rhodantha Blakely and Steedman is unusual amongst eucalypts in that it produces very few (1-56) open flowers on each plant even at peak flowering, the flowers are large (up to $7.5 \mathrm{~cm}$ across) and birds are the main pollinators (McNee, 1986). Sampson et al. (1989) reported variation 
between single-locus estimates of $\hat{t}$ based on different loci, heterogeneity of pollen pool allele frequencies between trees with the same maternal genotype and multilocus estimates of $\hat{t}$ which exceed mean single-locus estimates in this species. Both temporal and spatial heterogeneity of pollen pool allele frequencies over maternal plants were suggested as possible factors contributing to this variation in estimates.

In this study, temporal changes in allele frequencies in the pollen pool of a sample of $E$. rhodantha plants over a flowering season are described. This investigation was undertaken to determine whether such changes are potentially a significant source of bias in estimates of outcrossing based upon the assumption of temporal homogeneity of pollen pool allele frequencies in E. rhodantha.

\section{MATERIALS AND METHODS}

Twenty five plants were selected for study. These plants form part of a remnant of 80 ha of uncleared vegetation containing two stands of $E$. rhodantha and were selected to duplicate the sample used in a previous investigation of mating system parameters (Sampson et al., 1989). The distribution of plants within the study area is shown in fig. 1 and has been described in more detail in Sampson et al. (1989). Flowering phenology within this stand had been monitored over three years and plants were known to differ in the number of flowers they produce and the time of onset, maximum and final flowering (McNee, 1986). The flowering time differences also appeared to be consistent over years although the total numbers of flowers varied widely betweeen years.

The number of flowers releasing pollen on each plant was estimated by counting the number of flowers with their staminal rings intact at approximately monthly intervals during 1986. In a detailed study of flowering phenology in E. rhodantha, McNee (1986) found that flowers were protandrous. Most of the pollen was shed from the anthers within six or seven days after anthesis whilst the stigma did not become receptive until about 12 days after anthesis. The staminal ring remained intact for about ten days following the shedding of the operculum.

Flowers with dehisced staminal rings were tagged during the 1986 flowering season on 11 of the sampled plants. 1986 was a poor flowering season and very few mature fruit were produced.
Four or five fruit were collected from each of six plants in July 1987, and the seed of each plant was bulked. Fifty seedlings with newly emerged cotyledons from each plant were assayed for four polymorphic loci: alcohol dehydrogenase (Adh-1), glutamate oxaloacetate transaminase (Got-1 and Got-2) and malate dehydrogenase $(M d h-2)$ by methods described in Moran and Hopper (1983). The genotypes of 24 plants from which pollen or seed were available had been determined previously for these loci by methods described in Sampson et al. (1989).

\section{Estimation of pollen pool allele frequencies}

Pollen pool allele frequencies were estimated for the sample plants by five procedures modified from those of Fripp et al. (1987).

(1) By a single-locus maximum likelihood estimation procedure based on the mixed mating model using the computer program of Ritland and Jain (1981). This procedure jointly estimates pollen allele frequencies $\left(p_{i}\right)$ and the level of outcrossing $(\hat{t})$. The data used were the observed genotype frequencies in progeny arrays from six of the 24 plants. (Maximum likelihood estimation, progeny genotypes).

(2) From the genotypes of 24 plants from which pollen or seed was available to determine the genotype. (Adult genotypes).

(3) From the genotypes of 24 adult plants after weighting each plant's genotype by the plant's estimated relative fecundity. (Adult genotypes + fecundity).

(4) From the genotypes of 24 adult plants accounting for phenology using equation (1) (entire stand) or equations (1) and (2) (plant $i$; see below). All $F_{i}$ (the number of flowers at time $x$ for plant $i$ ) were set to one. (Adult genotypes + phenology).

(5) From the genotypes of 24 adult plants allowing for phenology using equation (1) (entire stand) or equations (1) and (2) (plant $i$; see below) and the number of flowers per plant $\left(F_{i}\right)$. (Adult genotypes + phenology + fecundity).

Methods (1), (2) and (3) assume that the allele frequencies are constant throughout the flowering season. Method (3) also assumed that the proportional contribution of each plant depends directly on its relative fecundity. Methods (1), (2) and (4) assume that each plant contributes the same amount of pollen to the pollen pool and method (5) assumes that each flower contributes the same amount of pollen to the pollen pool. The "mean" pollen pool allele frequencies over the entire 


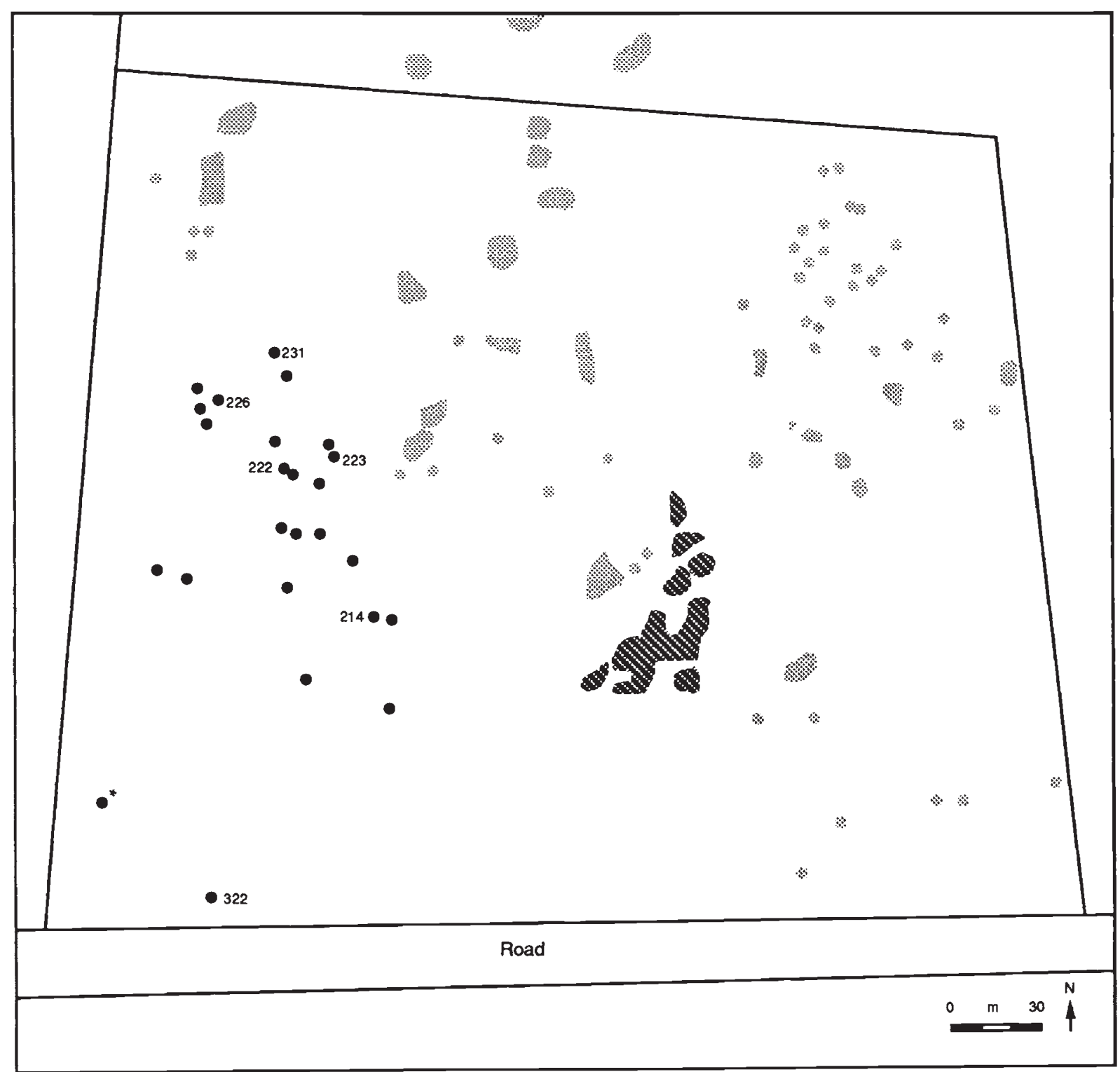

Figure 1 Diagrammatic representation of the remnant stand showing the distribution of E. rhodantha. The six plants from which progeny samples were collected are numbered. (O) Sampled plant, (\$) Other E. rhodantha, (\$) E. rhodantha burnt April 14th, 1986, ( $\longrightarrow$ ) Fence, * Genotype unknown. The scale is approximate.

season for methods (4) and (5) were calculated as the means of the frequencies at each recorded date.

Allele frequencies in the pollen pool at time $(x)$ were estimated using formulae modified from those of Fripp et al. (1987). The formulae were developed for the mass flowering $E$. regnans where a beta frequency distribution was suggested to approximate the unimodal flowering of this eucalypt. Field observations indicate that the opening of flowers on E. rhodantha does not follow a unimodal pattern and direct counts of the number of flowers releasing pollen could be made for this species since it has relatively few open flowers at any one time. $P_{j}(x)$ the frequency of allele $j$ at time $x$ in the total pollen pool of the subpopulation was estimated as:

$$
P_{j}(x)=\frac{B_{j}(x)}{\sum_{j=1}^{m} B_{j}(x)}
$$


where

$$
\begin{aligned}
B_{j}(x)= & \sum_{i=1}^{n} F_{i} A_{i j} \\
F_{i}= & \text { the number of flowers at time } x \text { for } \\
& \text { plant } i \\
n= & \text { number of plants in the } \\
& \text { subpopulation } \\
m= & \text { number of alleles } \\
A_{i j}= & \text { allele weighting of plant } i \text { for } \\
& \text { allele } j .
\end{aligned}
$$

The allele weighting, $A_{i j}$ is 2 if plant $i$ is homozygous for allele $j, 1$ if it is heterozygous for allele $j$ and 0 if it is homozygous or heterozygous for alleles other than $j$.

$p_{i j}(x)$ the frequency of allele $j$ at time $x$ in the pollen pool of plant $i$ was estimated by:

$$
p_{i j}(x)=\frac{b_{i j}(x)}{\sum_{j=1}^{m} b_{i j}(x)}
$$

where

$$
b_{i j}(x)=\sum_{k=1}^{n} F_{k} A_{k j} W_{i k}
$$

$k$ refers to the plant whose contribution to the outcross pollen pool of plant $i$ is being estimated. $W_{i k}$ represents the relative contribution on the $k$ th plant to the outcross pollen pool of plant $i$. $W_{i k}=0$ for $k=i$. The other $(n-1) W_{i k}$ values for each plant were set at one under the assumption that flowers from each plant contributed equally to the outcross pollen pool of every other plant in the stand.

\section{Testing the fit of data to model assumptions}

The allele frequencies estimated by the above procedures were also compared for their abilities to predict the frequencies of genotypes in the progeny arrays of six plants sampled in 1987 for fruit set in 1986.

An estimate of the outcrossing rate $(\hat{t})$ based on the mixed mating model was obtained by maximum likelihood procedures for each of the five estimates of pollen pool allele frequency for each of the four loci. The assumptions of the mixed mating model are: (1) each mating event is the result of either a random outcross or self-fertilisation, (2) the probability of an outcross is independent of maternal genotype, (3) selection does not intervene between fertilisation and determination of the progeny genotypes, and usually, (4) outcross pollen pool allele frequencies are independent of maternal genotype. Method (1) jointly estimates $\hat{t}$ and pollen allele frequencies. For the remaining four methods the $\hat{t}$ giving the maximum likelihood were found by the method of Fripp et al. (1987) in which the expected genotype frequencies in the progeny were obtained using the conditional probabilities given in Clegg et al. (1978).

The goodness-of-fit of data with the model expectations may be detected using a $\chi^{2}$ statistic (Ritland, 1983) but these data generated numerous expected numbers of progeny less than one and were therefore not suitable for such analyses. Instead, the methods of calculating pollen allele frequencies were compared using the sum of $10 \mathrm{~g}$ likelihoods for all plants (Kendall and Stuart, 1961; Fripp et al., 1987).

\section{RESULTS}

\section{Fecundity and flowering phenology}

Flowers were observed on plants between March and November in 1986 (table 1, fig. 2). The maximum number of pollen-shedding flowers in the sample was recorded in June. The number of flowers with staminal rings intact per plant was low even at the peak of the season (mean $=3 \cdot 76$ for June, day 165). The mean number of flowers of any developmental stage between anthesis and the complete loss of stamens per plant in June was $5 \cdot 6$ (range 1-56; McNee, 1986).

Plants differed in fecundity. The most fecund plant recorded, No. 322 , contributed 20.42 per

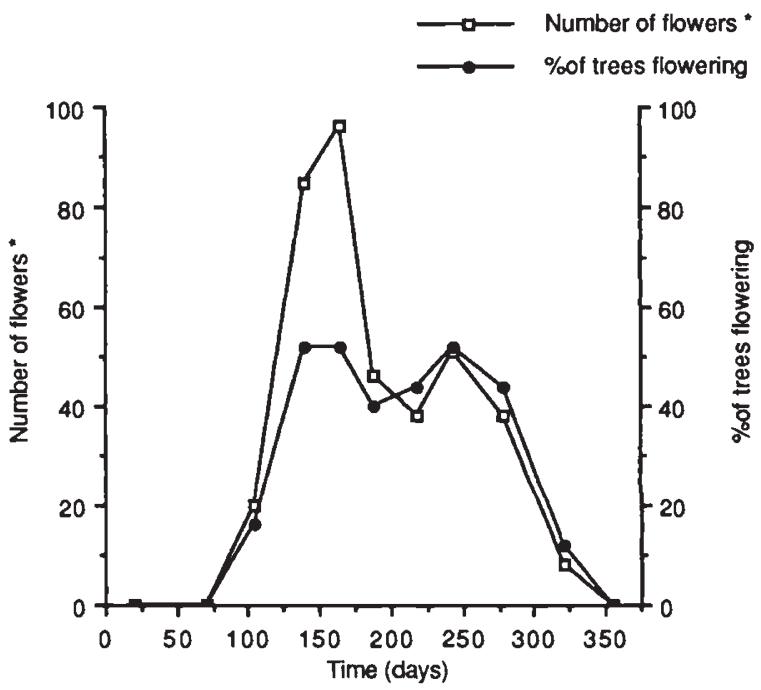

Figure 2 Estimated number of flowers releasing pollen and proportion of plants releasing pollen in the sample during 1986. Day 1 is January 1, 1986. *, open flowers with intact staminal rings. 
Table 1 Observed number of flowers with staminal rings intact and floral phenology for the 25 plants

Flower numbers

\begin{tabular}{|c|c|c|c|c|c|c|c|c|c|c|c|c|c|}
\hline \multirow{2}{*}{$\begin{array}{l}\text { Plant } \\
\text { No. }\end{array}$} & \multicolumn{13}{|c|}{ Flowering time $\mathrm{e}^{\mathrm{a}}$} \\
\hline & 20 & 71 & 104 & 146 & 165 & 189 & 218 & 244 & 279 & 322 & 355 & Total & $\%^{\mathrm{b}}$ \\
\hline 322 & - & - & - & 31 & 28 & 9 & 5 & 3 & 2 & - & - & 78 & 20.42 \\
\hline 214 & - & - & - & 8 & 12 & 5 & 3 & 15 & 9 & - & - & 52 & $13 \cdot 61$ \\
\hline 218 & - & - & - & 10 & 11 & 6 & 6 & 3 & 1 & - & - & 37 & $9 \cdot 69$ \\
\hline 208 & - & - & 7 & 9 & 8 & - & - & 3 & - & - & - & 27 & 7.07 \\
\hline 209 & - & - & - & 5 & 7 & 8 & 2 & - & - & - & - & 22 & 5.76 \\
\hline 225 & - & - & - & - & 4 & 5 & 9 & 2 & - & - & - & 20 & $5 \cdot 24$ \\
\hline 160 & - & - & - & - & 3 & 3 & 4 & 7 & 4 & - & - & 21 & $5 \cdot 50$ \\
\hline 324 & - & - & - & - & - & - & 1 & 6 & 9 & 3 & - & 19 & 4.97 \\
\hline 217 & - & - & - & 1 & 7 & 5 & - & 1 & 4 & - & - & 18 & $4 \cdot 71$ \\
\hline 206 & - & - & - & 6 & 6 & 2 & 2 & - & - & - & - & 16 & $4 \cdot 19$ \\
\hline 228 & - & - & 7 & - & 6 & - & - & - & - & - & - & 13 & 3.40 \\
\hline 219 & - & - & - & - & 1 & 2 & 2 & 4 & 1 & - & - & 10 & $2 \cdot 62$ \\
\hline 230 & - & - & - & 6 & 2 & - & - & - & 2 & - & - & 10 & $2 \cdot 62$ \\
\hline 222 & - & - & - & - & - & 1 & - & 2 & 3 & 3 & - & 9 & $2 \cdot 36$ \\
\hline 223 & - & - & - & 1 & 1 & - & 2 & 3 & 1 & - & - & 8 & 2.09 \\
\hline 207 & - & - & 4 & - & - & - & - & 1 & - & 2 & - & 7 & 1.83 \\
\hline 231 & - & - & - & 4 & - & - & 2 & 1 & - & - & - & 7 & 1.83 \\
\hline 212 & - & - & - & 2 & - & - & - & - & - & - & - & 2 & 0.52 \\
\hline 229 & - & - & 2 & - & - & - & - & - & - & - & - & 2 & 0.52 \\
\hline 326 & - & - & - & - & - & - & - & - & 2 & - & - & 2 & 0.52 \\
\hline 226 & - & - & - & 1 & - & - & - & - & - & - & - & 1 & 0.26 \\
\hline 213 & - & - & - & 1 & - & - & - & - & - & - & - & 1 & 0.26 \\
\hline 221 & - & - & - & - & - & - & - & - & - & - & - & - & - \\
\hline 224 & - & - & - & - & - & - & - & - & - & - & - & - & - \\
\hline 227 & - & - & - & - & - & - & - & - & - & - & - & - & - \\
\hline
\end{tabular}

${ }^{a}$ Number of days after January 1, 1986. ${ }^{b}$ Percentage of total flowers with intact staminal rings recorded in the sample.

cent of the flowers over the entire season whilst eight plants contributed less than 1 per cent each. The four most fecund plants produced 50 per cent of the flowers recorded. The total numbers of flowers produced was underestimated since only flowers with intact staminal rings were recorded and it was possible for flowers to open, mature and begin to loose their stamens between the monthly counts. However, the observed differences in fecundity were consistent with the observations of McNee (1986).

Plants also differed for the first, maximum and last date at which flowers with intact staminal rings were recorded. Similar observations were made for total flowers per plant (McNee, 1986). Observations also demonstrated that the flowering seasons of some plants did not overlap and that flower production was staggered throughout the plants' flowering season.

The estimated proportion of plants flowering and the total number of flowers releasing pollen in the sample are shown in fig. 2. The pattern of flower production was similar to that suggested by Fripp et al. (1987) as likely to lead to temporal heterogeneity of pollen pool allele frequencies.
High proportions of pollen-shedding flowers were often produced by one to a few plants and different plants were the dominant flower producers at different times.

Approximately 67 per cent of flowers were estimated to have been releasing pollen between day 146 (May) and day 279 (September). The flowers were counted when they had intact staminal rings and were therefore aged between 0 and 10 days. Since $E$. rhodantha flowers become receptive approximately 12 days after anthesis, the flowers would have become receptive between two and twelve days after being scored. It was estimated that approximately 68 per cent of the total season's flowers had receptive stigmas during this period. These observations were consistent with those of McNee (1986).

\section{Allele frequencies in the pollen pool}

Allele frequencies in the pollen pool of the sampled stand, estimated by the five different methods described above, for four polymorphic loci are plotted over time in figs. 3-6. Methods (1-3) are shown as functions of time even though they are 


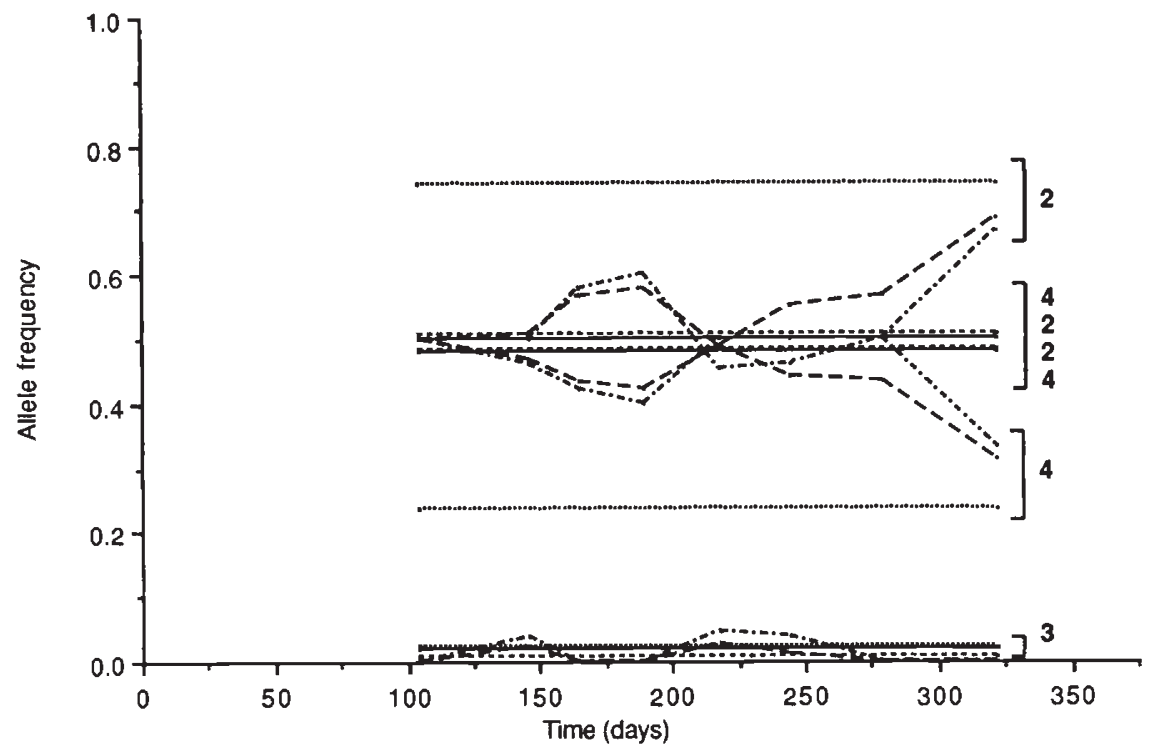

Figure 3 Estimated allele frequencies at the $A d h-1$ locus in the pollen pool of the sampled E. rhodantha. Methods 1 ( ....), $2(-), 3(-.--), 4(-\cdot-\cdot-), 5(---)$. See text for explanation. Lines representing alleles are indicated by numbers, e.g., $2=A d h-12$.

calculated only once under the assumption that pollen pool allele frequencies were constant throughout the flowering season.

Estimates of pollen pool allele frequencies at the Adh-1 locus made by method (1) differed substantially from those made by the other methods and estimates of allele frequencies changed over the flowering season when flowering phenology was taken into account (methods (4) and (5)). Different alleles became the most common allele at different times but, during the period of maximum pollination activity (days 146-279), allele frequencies estimated by methods (2-5) were relatively similar.

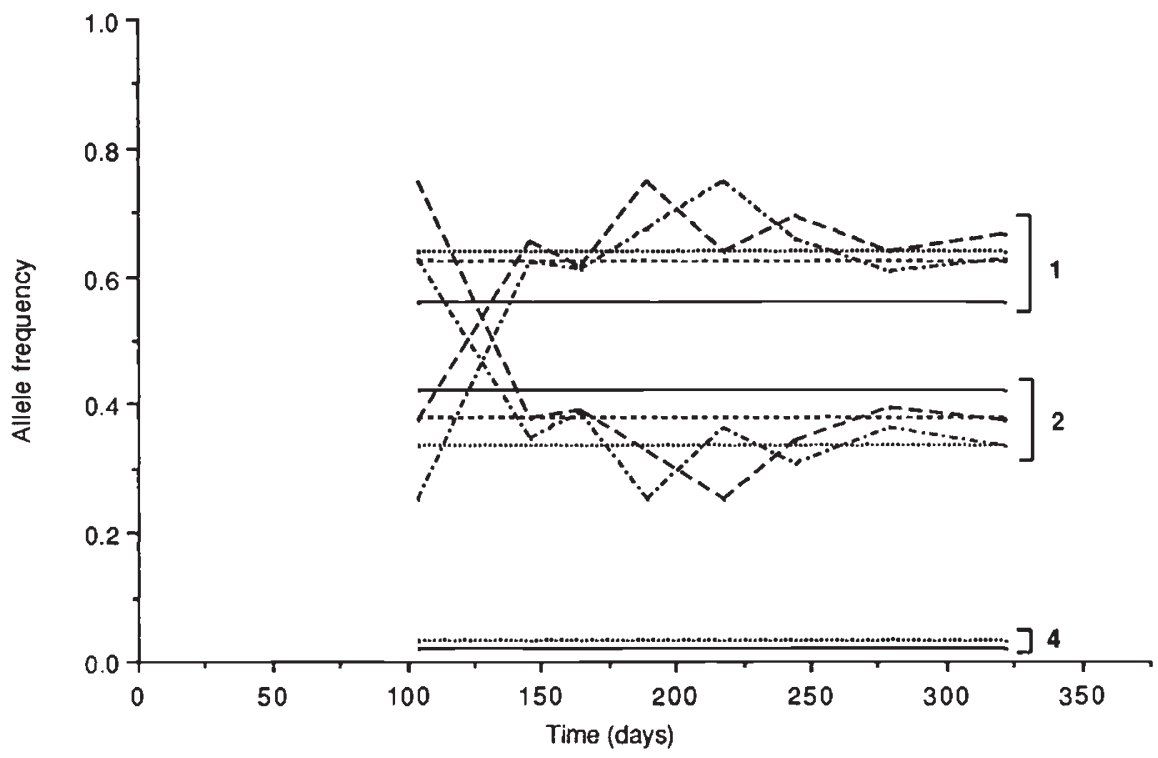

Figure 4 Estimated allele frequencies at the Got-1 locus in the pollen pool of the sampled E. rhodantha. Methods 1 (....), $2(-), 3(---), 4(-\cdot--), 5(---)$. See text for explanation. Lines representing alleles are indicated by numbers, e.g., $2=$ Got -12 . 


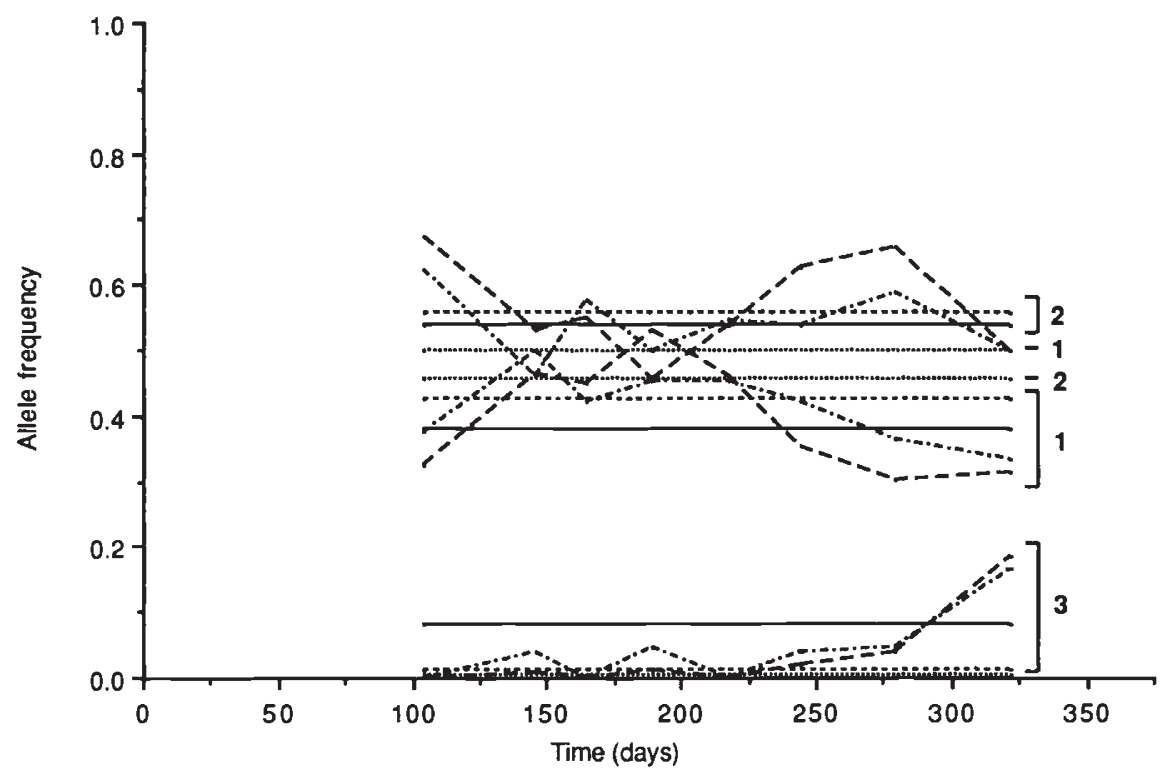

Figure 5 Estimated allele frequencies at the Got-2 locus in the pollen pool of the sampled E. rhodantha. Methods 1 ( ....), $2(-), 3(---), 4(-\cdot-\cdot-), 5(---)$. See text for explanation. Lines representing alleles are indicated by numbers, e.g., $2=$ Got -22 .

For the Got-1 locus, estimates of allele frequencies for the first record of the season was substantially different when phenology was taken into account (methods (4) and (5)). When fecundity or phenology was allowed for (methods (3-5)), the frequency of the rare Got-1 4 allele was estimated as zero. The frequencies of alleles changed over the flowering season and the order of frequency of the common alleles reversed in the early part of the season (between days 104 and 139). Allele frequencies also changed substantially between the middle of the season when the majority of pollina-

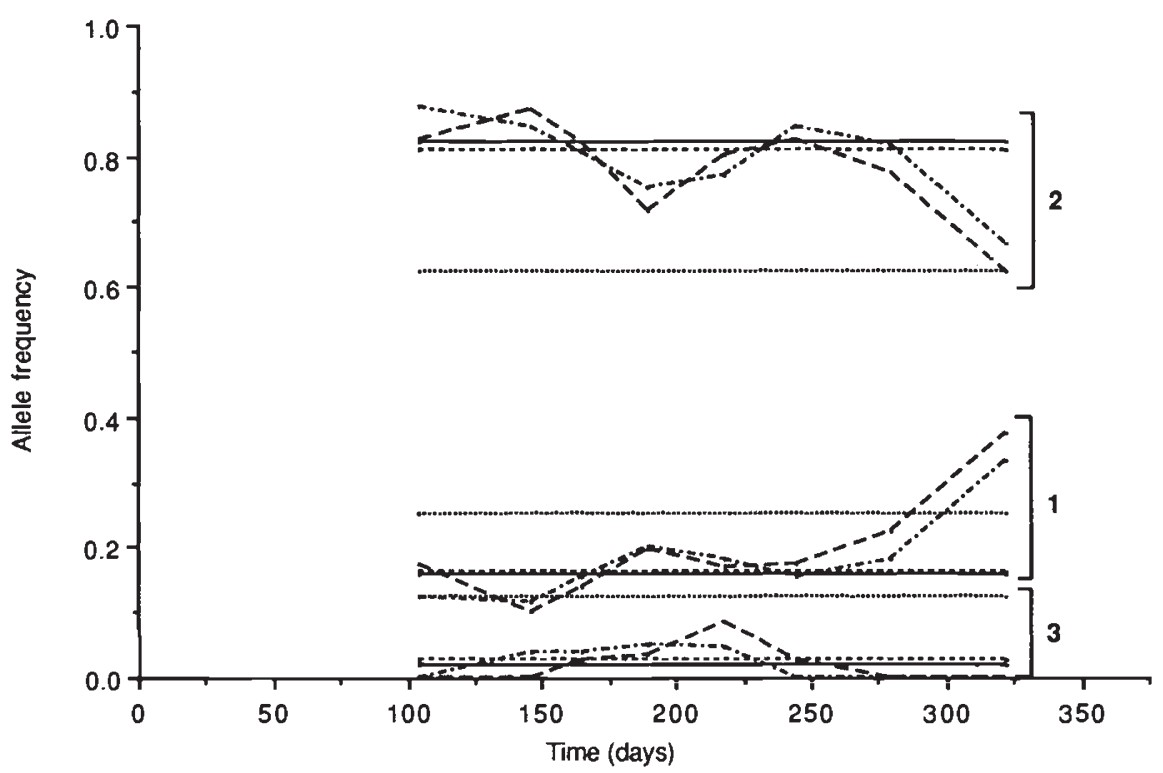

Figure 6 Estimated allele frequencies at the $M d h-2$ locus in the pollen pool of the sampled E. rhodantha. Methods 1 (...), $2(-), 3(----), 4(-\cdot-\cdot), 5(--)$. See text for explanation. Lines representing alleles are indicated by numbers, e.g., $2=M d h-22$. 
tions are proposed to have occurred, and the end of the season. Such a change could be significant for late-flowering plants. For example, taking phenology and recundity into account, the frequency of the most common allele was 0.75 on day 218 in the middle of the season and then dropped back to 0.61 by day 279 .

For the Got-2 locus, allele frequencies estimated by methods (4) and (5) also changed during the flowing season. Estimates of the frequency of the rare Got-2 3 allele based on adult genotypes (method (2)) differed substantially from those estimated for the end of the season when phenology was taken into account. During the period when the bulk of pollinations would have occurred (days 146-279), all of the methods gave similar estimates except that the difference between the frequencies of the more common alleles became more pronounced at the end of this period when when both phenology and fecundity were taken into account (method (5)).

Methods (2-5) gave similar estimates of allele frequencies for the $M d h-2$ locus although when phenology was taken into account, the frequencies changed throughout the season. When $\hat{t}$ and $p$ were jointly estimated (method (1)), the values of the $M d h-22$ and $M d h-23$ alleles differed substantially from those estimated by methods (2-5). However, during the middle of the main pollination period, the frequencies estimated by methods (4) and (5) approached that of method (1).

\section{Estimates of outcrossing rate}

Estimates of outcrossing rate $(\hat{t})$ for the four loci are shown in tables 2-5. Estimates differed between loci and between methods of calculating allele

Table 2 Estimates of outcrossing rate and total log likelihoods for the $A d h-1$ locus based on five alternative methods of estimating allele frequencies in the outcross pollen pools. Methods described in text.

\begin{tabular}{llll}
\hline & & \multicolumn{2}{l}{-Log likelihood } \\
\cline { 3 - 4 } Estimation method & $\hat{t}$ & Total & Plant No. 222 \\
\hline $\begin{array}{l}\text { 1. Max. likelihood } \\
\text { estimate, progeny }\end{array}$ & 0.49 & 357.63 & 54.72 \\
$\begin{array}{l}\text { genotypes } \\
\text { 2. Adult genotypes }\end{array}$ & 0.84 & 135.10 & 20.64 \\
$\begin{array}{l}\text { 3. Adult genotypes } \\
\text { + fecundity }\end{array}$ & 0.91 & 130.43 & 19.41 \\
$\begin{array}{l}\text { 4. Adult genotypes } \\
\quad \text { + phenology }\end{array}$ & 0.89 & 131.33 & 19.66 \\
$\begin{array}{l}\text { 5. Adult genotypes } \\
\text { + fecundity } \\
\text { + phenology }\end{array}$ & 0.88 & 132.25 & 19.91 \\
\hline
\end{tabular}

frequencies but the number of plants sampled was small.

Overall, means of the single-locus estimates were similar for the methods (2-5) (table 6) and higher than the mean of single locus estimate of $\hat{t}$ when it was jointly estimated with $p$.

Three plants (numbers 324, 22 and 207) have been identified by this study as having flowers

Table 3 Estimates of outcrossing rate and total log likelihoods for the Got-1 locus based on five alternative methods of estimating allele frequencies in the outcross pollen pools. Methods described in text

\begin{tabular}{llll}
\hline & & \multicolumn{2}{l}{-Log likelihood } \\
\cline { 3 - 4 } Estimation method & $\hat{t}$ & Total & plant No. 222 \\
\hline $\begin{array}{l}\text { 1. Max. likelihood } \\
\text { estimate, progeny } \\
\text { genotypes }\end{array}$ & 0.56 & 230.33 & 41.73 \\
$\begin{array}{l}\text { 2. Adult genotypes } \\
\text { 3. Adult genotypes } \\
\quad \text { +fecundity }\end{array}$ & 0.57 & 231.07 & 39.04 \\
$\begin{array}{l}\text { 4. Adult genotypes } \\
\quad+\text { phenology }\end{array}$ & 0.52 & 201.66 & 20.01 \\
$\begin{array}{l}\text { 5. Adult genotypes } \\
\quad+\text { fecundity } \\
\quad \text { + phenology }\end{array}$ & 0.50 & 204.81 & 20.09 \\
\hline
\end{tabular}

Table 4 Estimates of outcrossing rate and total log likelihoods for the Got-2 locus based on five alternative methods of estimating allele frequencies in the outcross pollen pools. Methods described in text.

\begin{tabular}{|c|c|c|}
\hline Estimation method & $\hat{t}$ & $\begin{array}{l}\text { - Log } \\
\text { likelihood }\end{array}$ \\
\hline $\begin{array}{l}\text { 1. Maximum likelihood estimate, } \\
\text { progeny genotypes }\end{array}$ & 0.71 & $323 \cdot 11$ \\
\hline 2. Adult genotypes & 0.57 & $306 \cdot 70$ \\
\hline 3. Adult genotypes + fecundity & $0 \cdot 61$ & $315 \cdot 36$ \\
\hline 4. Adult genotypes + phenology & 0.57 & 307.59 \\
\hline $\begin{array}{l}\text { 5. Adult genotypes + fecundity } \\
\text { + phenology }\end{array}$ & 0.56 & $309 \cdot 41$ \\
\hline
\end{tabular}

Table 5 Estimates of outcrossing rate and total log likelihoods for the Mdh2 locus based on five alternative methods of estimating allele frequencies in the outcross pollen pools. Methods decribed in text.

\begin{tabular}{llc}
\hline Estimation method & $\hat{\imath}$ & $\begin{array}{c}\text { Log } \\
\text { likelihood }\end{array}$ \\
\hline $\begin{array}{l}\text { 1. Maximum likelihood estimate } \\
\text { progeny genotypes }\end{array}$ & 0.68 & $245 \cdot 55$ \\
$\begin{array}{l}\text { 2. Adult genotypes } \\
\text { 3. Adult genotypes + fecundity }\end{array}$ & $1 \cdot 00$ & $265 \cdot 96$ \\
$\begin{array}{l}\text { 4. Adult genotypes + phenology } \\
\text { 5. Adult genotypes + fecundity } \\
\quad \text { phenology }\end{array}$ & $1 \cdot 00$ & $259 \cdot 11$ \\
& $1 \cdot 00$ & $265 \cdot 16$ \\
\hline
\end{tabular}


Table 6 Mean single locus estimates of outcrossing rate for the four loci (Adh-1, Got-1, Got-2, Mdh-2) and the five alternative methods of estimating allele frequencies in the outcross pollen pools. Methods described in text.

\begin{tabular}{ll}
\hline Estimation method & Mean $\hat{t}$ \\
\hline 1. Maximum likelihood estimate, progeny & $0 \cdot 61$ \\
genotypes & $0 \cdot 75$ \\
2. Adult genotypes & $0 \cdot 76$ \\
3. Adult genotypes + fecundity & $0 \cdot 75$ \\
4. Adult genotypes + phenology & 0.74 \\
5. Adult genotypes + fecundity + phenology & \\
\hline
\end{tabular}

which opened late in the 1986 season. These plants have a higher potential of being pollinated outside the main pollination period. Since plants tend to flower at relatively the same time each year (McNee, 1986), one might expect any bias to be apparent in randomly sampled seed.

Estimates of outcrossing rate based on randomly sampled seed from 22 of the sampled plants, set over several years, have been made (Sampson et al., 1989). Plants No. 222 and No. 207 were removed from these data and joint maximum likelihood estimates of $\hat{t}$ and $p$ recalculated (plant No. 324 was not included in that survey). These estimates are shown in table 7 .

If estimates of $\hat{t}$ had been biased down by temporal heterogeneity in the pollen pool then one would expect some of this bias to be removed when the "late" plants were removed from calculations. The recalculated estimates of $\hat{t}$ although higher, were not significantly different from those made previously for all the plants.

The level of outcrossing found when $\hat{t}$ and $p$ were jointly estimated for the $A d h-1$ locus was substantially lower than estimates made by any of

Table 7 Maximum likelihood estimates of outcrossing rate based upon randomly sampled progeny arrays of 22 plants sampled in subpopulation 1 , and for the same group of plants without the "late" flowering plants No. 222 and No. 207. See Sampson et al. (1989) for details of the collection and analyses of data. Standard errors in parentheses. $n$, number of maternal plants sampled.

\begin{tabular}{|c|c|c|}
\hline \multirow[b]{2}{*}{ Locus } & \multicolumn{2}{|l|}{ Plants sampled } \\
\hline & $\begin{array}{l}\text { Total } \\
\hat{t}\end{array}$ & $\begin{array}{l}\text { Without "late" plants } \\
(n=20) \\
\hat{t}\end{array}$ \\
\hline$A d h-1$ & $0.32(0.06)$ & $0.34(0.09)$ \\
\hline Got-1 & $0.64(0.08)$ & $0.68(0.09)$ \\
\hline Got-2 & $0.79(0.08)$ & $0.80(0.08)$ \\
\hline$M d h-2$ & $0.58(0.09)$ & $0.58(0.09)$ \\
\hline Mean & $0.58(0.04)$ & $0.60(0.04)$ \\
\hline
\end{tabular}

the other methods. The method 1 estimate, $(\hat{t}=$ 0.49 ), indicated predominant inbreeding rather than outbreeding and had a much larger log likelihood value. There were substantial improvements in the log likelihood values when $p$ was estimated using the adult genotypes but using the information on fecundity and/or phenology to estimate pollen pool allele frequencies did not result in further substantial improvements.

The multilocus estimate of outcrossing for the data collected in 1986 was 0.71 (s.e. 0.03 ). Since multilocus estimates of outcrossing rate are less affected by selection and non-random mating (Ritland and Jain, 1981), the multilocus estimate is inferred to the "best" estimate of outcrossing for these data and provides a point of comparison for the single-locus estimates. For the $A d h-1$ locus, jointly estimating $\hat{t}$ and $p$ (method (1)) led to an underestimate of $\hat{t}$ relative to the multilocus value whereas all other methods led to overestimates of $\hat{t}$.

Estimates of $\hat{t}$ for the Got-1 locus were similar but improved when fecundity and/or phenology were taken into account. In this case the improvement appeared to be mainly due to better estimates for the "late" flowering plant number 222. The improved estimates did however not approach the multilocus estimate of $\hat{t}$.

The estimates of $\hat{t}$ for the Got-2 locus for methods (2-5) were similar and lower than the method (1) estimate. The best likelihood was obtained by using adult genotypes to calculate pollen allele frequencies (method (2)) but method (1) gave the outcrossing rate closest to the multilocus estimate.

For the $M d h-2$ locus, the estimates of $\hat{t}$ made by methods (2-5) were $1 \cdot 00$, suggesting random mating and were substantially higher than the estimates obtained using method (1) which jointly estimates $\hat{t}$ and pollen pool allele frequencies. The estimated frequencies of the most common and most rare alleles made by method (1) were less extreme than those for methods (2-5) (fig. 6). In contrast to the other loci, method (1) gave the best log likelihood for the $M d h-2$ locus and the $\hat{t}$ most similar to the multilocus $\hat{t}$. All other methods led to poorer predictions for this loclis.

\section{DISCUSSION}

This investigation demonstrates that temporal heterogeneity in the allele frequencies of the pollen pool occurs during the flowering season of $E$. rhodantha. A similar observation was made for an 
isolated stand of the mass flowering forest tree $E$. regnans (Fripp et al., 1987).

The methods used to estimate pollen gene frequencies had several limitations. First, flower counts were made at monthly intervals and the flowering of some plants may not have been detected. For example, method (1) (progeny arrays) and method (2) (adult genotypes) indicate that the Got-1 4 allele was present in the pollen pool at low frequencies. Methods that took phenology or fecundity into account did not detect this allele probably because flowering had occurred between the dates recorded or because the pollen carrying this allele came from outside this subpopulation.

Secondly, one of the assumptions of the estimation procedures was that the contribution of a plant to the pollen pool of another plant was independent of the distance between them and that the plants in the sample represented all the contributors to the pollen pool of any plant within it. This is unlikely to be true for some of the plants in the subpopulation. However, previous investigations suggest that gene flow within populations of $E$. rhodantha is restricted and that the area within the fence shown in fig. 1 contains several neighbourhoods (Sampson et al., 1989). This is consistent with reports of neighbourhood areas and sizes for other plant species, which are often small (Crawford, 1984). Furthermore, observations of mean flower-to-flower distances travelled by two pollinator species of $E$. rhodantha were $10.4 \mathrm{~m}$ and $15.9 \mathrm{~m}$ (McNee, 1986). Even allowing for pollen carry-over, the surveyed plants should include the majority of contributors to the pollen pools of at least some of the plants from which progeny were sampled. The many similarities between allele frequency estimates based on progeny arrays (method (1)) or on adult genotypes (methods 2-5) support this suggestion.

Despite the above limitations, the estimates of pollen pool allele frequencies suggest that temporal heterogeneity may be a source of bias in estimates of $\hat{t}$ that assume temporal homogeneity of pollen pool allele frequencies. In an expermental population of Zea mays L., Bijlsma et al. (1986) found that temporal variation in the allele frequencies of the pollen pool may have contributed to low estimates of $\hat{t}$ at two marker loci that themselves affect time of flowering or are associated with alleles of loci that affect time of flowering. In contrast, Fripp et al. (1987) found no evidence of biased single-locus $\hat{t}$ estimates due to the demonstrated temporal heterogeneity of allele frequencies in E. regnans.
As in the E. regnans study, taking temporal heterogeneity into account did not always result in higher or improved estimates of $\hat{t}$ in $E$. rhodantha and in only one case (Got-1) could an improvement be attributed to a better estimate for a late-flowering plant. Furthermore, the better estimates were sometimes lower. This is contrary to expectations if the improvements were the result of removal of bias caused by the assumption of temporal homogeneity of allele frequencies in the pollen pool. It is therefore not surprising that improved estimates of $\hat{t}$ were sometimes obtained when the method used to calculate pollen pool allele frequencies allowed for fecundity but not phenology.

The effect of the temporal heterogeneity of allele frequencies in the sampled E. rhodantha was also examined by identifying plants whose stigmas were likely to sample a pollen pool different to that of the majority of plants ("late" plants) and, using data presented in Sampson et al. (1989), recalculating $\hat{t}$ without these "late" plants. If these "late" plants consistently sampled different pollen pools over several years then, assuming any effects were not negated by selection before the point of assay, one would expect the downward bias to be apparent in these data. Estimates were lower for three loci (Adh-1, Got-1 and Got-2) but the differences were not significant.

If there is temporal heterogeneity in the pollen pool then one would also expect such heterogeneity to be evident in the progeny arrays of homozygous maternal plants if the "late" plants were within this sample. Plants 222 and 207 were both Got-1 11 homozygotes but no significant heterogeneity was detected in the pollen pool of plants homozygous at this locus in the study by Sampson et al. (1989).

Overall, these findings indicate that temporal heterogeneity of allele frequencies in the pollen pool over the flowing season may have contributed to variation and downward bias in single-locus estimates of $\hat{t}$ in $E$. rhodantha at some loci but it does not account for the majority of the variation observed. Taking phenology and fecundity into account may lead to improvements in estimates for single loci but when a mean value is determined from several loci, the additional information on temporal heterogeneity seems unlikely to lead to any substantial improvements.

The findings of this investigation of the mallee $E$. rhodantha with its protracted, irregular flowering period are therefore similar to those of Fripp et al. (1987) for the mass-flowering forest tree, $E$. regnans although the two species have different 
flowering phenologies. Making observations of flowering phenology is useful to identify plants that may be potential sources of error in estimates of $\hat{t}$ which assume homogeneity of pollen pool allele frequencies. However, temporal variation in pollen pool allele frequencies is probably not a major source of bias in single-locus estimate $\hat{t}$ in E. rhodantha.

Acknowledgements We thank Dr Yvonne Fripp for useful discussions on this research and for providing the computer program to estimate $\hat{t}$ for individual plants, Shapelle McNee for advice on pollination biology, and Dr A. H. D. Brown for his comments on the original manuscript. This research was undertaken whilst JFS was the recipient of an Australian Commenwealth Postgraduate Research Award and was financially supported by the University of Western Australia and the Western Australian Department of Conservation and Land Management.

\section{REFERENCES}

ASHTON, D. H. 1975. Studies of flowering behaviour in Eucalyptus regnans F. Muell. Aust. J. Bot., 23, 399-411.

BAWA, K. S. 1983. Patterns of flowering in tropical plants. In Jones, C. E. and Little, R. J. (eds) Handbook of Experimental Pollination Biology, Van Nostrand-Reinhold, New York, pp. 394-410.

BIJLSMA, R., ALLARD, R. W. AND KAHLER, A. L. 1986. Nonrandom mating in an open-pollinated maize population. Genetics, 112, 669-680.

BRown, A. H. D. AND ALlARD, R. W. 1970. Estimation of the mating system in open-pollinated maize populations using isozyme polymorphisms. Genetics, 66, 133-145.

CLEGG, M. T., KAHLER, A. L. AND ALLARD, R. W 1978. Estimation of the life cycle components of selection in an experimental plant population. Genetics, 89, 765-792.

CRAWFORD, T. J. 1984. What is a population? In Shorrocks, B. (ed.) Evolutionary Ecology, Blackwell Scientific Publications, Oxford, pp. 135-173.

ENNOS, R. A. AND CLEGG, M. T. 1982. Effect of population substructing on estimates of outcrossing rate in plant populations. Heredity, 48, 283-292.
FLORENCE, R. G. 1964. A comparative study of flowering seed production in six blackbutt (Eucalyptus pilularis $\mathrm{Sm}$.) forest stands. Aust. For., 28, 23-33.

FRANKIE, G. W., BAKER, H. G. AND OPLER, P. A. 1974. Comparative phenological studies of trees in tropical wet and dry forests in the lowlands of Costa Rica. J. Ecol., 62, 881-919.

FRIPP, Y. J., GRIFFIN, A. R. AND MORAN, G. F. 1987. Variation in allele frequencies in the outcross pollen pool of Eucalyptus regnans F. Muell. throughout a flowering season. Heredity, 59, 161-171.

FYFE, J. L. AND BAILEY, N. T. J. 1951. Plant breeding studies in leguminous forage crops. 1. Natural cross-breeding in winter beans. J. Agric. Sci., 41, 371-378.

HANDEL, S. N. AND LE VIE MISHKIN, J. 1984. Temporal shifts in gene flow and seed set: evidence from an experimental population of Cucumis sativus. Evolution, 38, 1350-1357.

Kendall, M. G. AND STUART, A. 1961. The Advanced Theory of Statistics, Vol. 2. Inference and Relationship, Charles Griffin, London.

McNEE, S. 1986. Grad. Dip. Nat. Res. Thesis, Curtin University.

MORAN, G. F. AND HOPPER, S. D. 1983. Genetic diversity and the insular population structure of the rare granite rock species, Eucalyptus caesia Benth. Aust. J. Bot., 31, 162-172.

O'MALLEY, D. M. AND BAWA, K. S. 1987. Mating system of a tropical rain forest tree species. Amer. J. Bot., 74, 11431149.

RITLAND, K. 1983. Estimation of mating systems. In Tanksley, S. D. and Orton, T. J. (eds) Isozymes in Plant Genetics and Breeding, Elsevier, Amsterdam, pp. 289-302.

RITLAND, K. AND JAIN, S. 1981. A model for the estimation of outcrossing rate and gene frequencies using $n$ independent loci. Heredity, 47, 35-52.

SAMPSON, J. F., HOPPER, S. D. AND JAMES, S. H. 1989. The mating system and population genetic structure in a birdpollinated mallee, Eucalptus rhodantha. Heredity, 63, 383393.

SCHOEN, D. S. AND CLEGG, M. T. 1984. Estimation of mating system parameters when outcrossing events are correlated. Proc. Natl Acad. Sci. USA, 81, 5258-5262.

STAM, P. 1983. The evolution of reproductive isolation in closely adjacent plant populations through differential flowering. Heredity, 50, 105-118.

STERN, K. AND ROCHE, L. 1974. Genetics of Forest Ecosystems. Chapman and Hall, London.

WHEELWRIGHT, N. T. 1985. Competition for dispersers, and the timing of flowering and fruiting in a guild of tropical trees. Oikos, 44, 465-477.

YEH, F. C., BRUNE, A., CHELIAK, W. M. AND CHIPMAN, D. C. 1983. Mating system of Eucalyptus citriodora in a seed production area. Can. J. For. Res., 13, 1051-1055. 